\title{
Design and Research of Lead-acid Battery Inspection System for Coal Mine Transport Vehicles Based on PLC
}

\author{
Yong Tang, 2, a ${ }^{1,}$ Bo Li ${ }^{1,2}$ \\ ${ }^{1}$ CCTEG Shenyang Research Institute, Fushun Liaoning 113122, China \\ ${ }^{2}$ State Key Laboratory of Coal Mine Safety Technology, Fushun Liaoning 113122, China \\ ${ }^{a}$ Corresponding author Email: 364932392@qq.com
}

Keywords: Coal mine transport vehicles; Accumulator; Inspection system; High rate discharge.

\begin{abstract}
In order to improve the safety characteristics of coal mine lead-acid battery, this paper puts forward a design scheme of coal mine lead-acid battery inspection system based on PLC. Based on the working principle and characteristics of lead-acid batteries used in coal mine transportation vehicles, the inspection system of lead-acid batteries used in coal mine is designed, with emphasis on the voltage detection circuit and current detection circuit for charge/discharge test. The inspection system is used to inspect the high-rate discharge performance of lead-acid batteries used in coal mines and the capacity of lead-acid batteries.
\end{abstract}

\section{Introduction}

In recent years, due to the country's increased management of coal mine safety production and the improvement of underground workers' safety production awareness, the situation of underground safety production has been steadily improved, and the coal mine safety production has achieved remarkable results. However, the problem of safety in production is still grim, and the hidden dangers of accidents that endanger the smooth development of safety in production have not been thoroughly treated, so higher requirements are put forward for the safety and reliability of electrical equipment in coal mines. The performance of the main power supplies of coal mine production equipment, such as lead-acid battery explosion-proof battery forklift, explosion-proof battery coal truck and mine battery electric locomotive, is directly related to the smooth progress of underground safety production. In the process of battery development and delivery, type test is an important means to ensure product performance and prolong product life. Therefore, it is of great significance to develop a test device for lead-acid batteries used in coal mines to ensure the reliability of related equipment and improve the current situation of safe production in coal mines.

At present, there are many kinds of battery performance testing equipment in China, including internal resistance testing equipment, capacity testing equipment and comprehensive testing equipment. These equipments play an important role in battery research and development and factory type test. However, due to the discreteness of battery temperature change, cycle times, charging and discharging conditions, aging degree, etc., to accurately predict battery performance, it is necessary to fully consider its influencing factors and track and detect them in real time. In addition, it is necessary to establish a performance estimation model based on multivariate, which leads to the disadvantages of low measurement accuracy, low intelligence level and high price of the above equipment. Therefore, the development of new high-precision and high-intelligence battery testing equipment is a hot spot in the field of battery testing technology.

\section{Lead-acid battery for coal mine}

Lead acid battery used in coal mine is mainly composed of positive plate, negative plate, glass fiber partition board, ABS engineering plastic battery tank, battery cover and sulfuric acid electrolyte. The battery tank and battery cover are bonded with epoxy resin adhesive. When single lead-acid 
batteries used in coal mines are combined into batteries, special wires are used for welding connection, so as to reduce contact resistance, prevent sparks, and ensure safe use and smooth battery circuit under special conditions. In order to avoid short circuit of battery, all exposed parts of conductive body shall be covered with plastic insulating sheath. The casting interface of connecting conductor wire is coated with sealant to prevent sulfuric acid corrosion and ensure safe use. Special safety valve is adopted for mine lead-acid battery, which can open and close automatically, which not only ensures the air permeability of battery but also reduces the water consumption of electrolyte.

The lead-acid batteries used in coal mines can be divided into special lead-acid batteries, flame-proof start-up lead-acid batteries and flame-proof fixed lead-acid batteries according to different occasions. Coal mine special lead-acid batteries meet the requirements of the standard "MT 3342008 specifications for explosion-proof special power supply devices for coal mine lead-acid batteries". the maximum capacity of the batteries can reach $1200 \mathrm{~A} \cdot \mathrm{h}$ and the voltage can reach $336 \mathrm{~V}$. The special lead-acid battery in coal mine has strong self-recovery ability, and does not need complicated battery management system. Overcharge or overdischarge does little harm to the battery, so the performance of the battery can be recovered by charging with small current. Hydrogen is emitted during charging or discharging of special lead-acid batteries, especially in the later stage of charging, a large amount of water is electrolyzed to release flammable gas, which brings safety hazards to coal mine production. Explosion-proof start-up lead-acid batteries have thin internal plates and large areas. The acid liquid is in a colloidal state. It has the characteristics of less water loss during charging or discharging, no need for supplementary liquid maintenance, and high discharge rate. It is suitable for large currents such as vehicle startup Application occasions. The explosion-proof fixed lead-acid battery has a capacity of only $20 \mathrm{~A} \cdot \mathrm{h}$, which is a maintenance-free backup battery for mines. The battery will lose a lot of water when overcharged and affect the battery life.

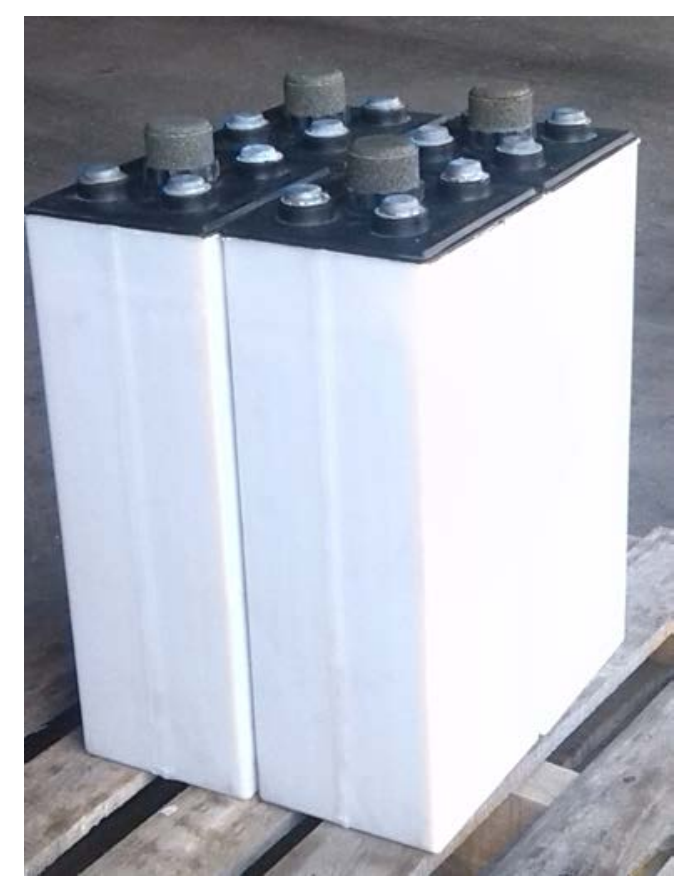

Figure 1 Lead-acid batteries for coal mines

\section{Inspection system of lead-acid battery for coal mine}

Combined with the characteristics of lead-acid batteries for coal mines and the requirements of "MT 658-2011 special lead-acid batteries for coal mines", the charging and discharging performance inspection system of lead-acid batteries is designed, which can complete the inspection items of constant current and constant voltage charging, constant current discharge and constant power 
discharge. The inspection system is mainly composed of processor, IGBT isolation drive, IGBT, system information detection circuit, signal processing circuit, display screen, operation panel, timer and constant temperature water tank. The composition of performance test system of lead-acid battery for coal mine is shown in Figure 1. The processor is the core of the whole control system, which is used to control and adjust the inspection system in the whole process. IGBT isolation driving circuit is used to isolate and amplify driving signals, realize positive pressure conduction and negative pressure turn-off, and improve the reliability of experimental devices. IGBT is used to control the charging and discharging circuits. The system information detection circuit is composed of voltage detection circuit, current detection circuit and temperature detection circuit, which is used to collect the operation information of the system and feed it back to the processor. The signal processing circuit adjusts the output signal of the system information detection circuit to realize signal isolation and conversion; The display screen is used for displaying the running state of the system; The operation panel is use for inputting external instruction during that test process; The timer is used to record the test operation time; The constant temperature water tank controls the test environment temperature through water circulation and heating device, so as to control the internal temperature of the battery and realize the constant temperature charge/discharge test; The system is connected with PC through Ethernet online interface, which can realize the storage and printing of test data, realize the centralized networking control of multiple testers, and have protection functions such as over-current, disconnection, reverse pole, overheating, power-off data saving, power-on automatic recovery and so on.

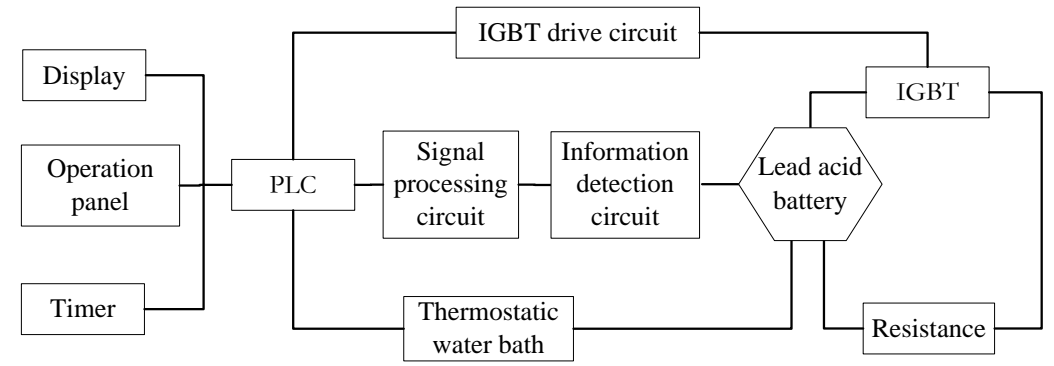

Figure 2. Structure of the performance inspection system for lead-acid batteries used in coal mines

\subsection{Current detection circuit}

The inspection system of lead-acid battery used in coal mine can realize the functions of constant current and constant voltage charging, constant current discharging, etc. The accuracy of current detection is directly related to the accuracy of the monitoring system. In this paper, Hall-type current sensor is used to detect the current of charge/discharge circuit in real time. The sensor has the characteristics of wide measuring range, fast response speed, good linearity and high stability of measurement results, and is widely used in industrial control, frequency conversion and power grid monitoring. The sensor is powered by $\pm 12 \mathrm{~V}$ power supply and outputs a signal proportional to the current value. The processor receives the current signal value of the sensor and calculates and processes the current value of the circuit. The wiring diagram of hall type current sensor is shown in Fig. 3.

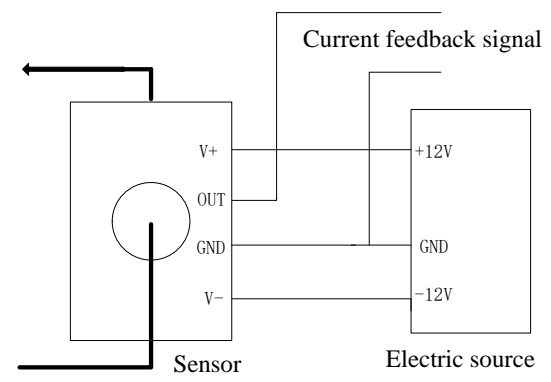

Figure 3. Connection diagram of Hall-type current sensor 


\subsection{Voltage detection circuit}

The voltage to be measured by the lead-acid battery inspection system for coal mine is a DC voltage variable, which can be measured by resistance voltage division to obtain an uninsulated low-voltage DC signal, which is then converted into a DC voltage proportional to it through linear optocoupler isolation and sent to A/D conversion measurement. The bridge-type voltage divider circuit is shown in Figure 4, and the measured part can be connected to both ends of a and b during measurement. In the figure, R1 and R2 are additional standard resistors, where R1=9R2. In this way, the voltage at both ends of $\mathrm{c}$ and $\mathrm{d}$ is $1 / 10$ of the measured voltage signal, and its voltage to ground is only equal to $1 / 20$ of the measured voltage.

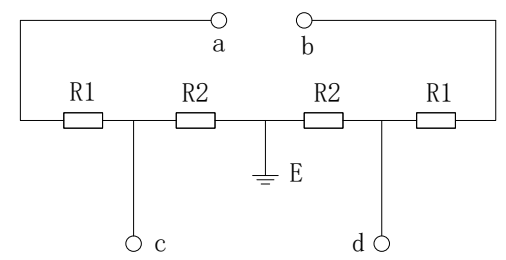

Figure 4. Voltage measurement circuit

\section{Conclusions}

Coal mine safety is a hot spot in all fields of contemporary society, and the safety of mining equipment plays a very important role in underground safety production. The inspection system of lead-acid batteries used in coal mines can complete the inspection of lead-acid batteries used in coal mines with different rules. The device has the characteristics of high precision, good stability and strong real-time performance.

\section{References}

[1] Aimin Liu, Jiajue Li, Yongxiang Li et al. Motion Control System Simulation of Cylindrical Linear Induction Motor used in Circuit Breaker Operating Mechanism. ICAL 2009, s henyang, 460-464, 2009.

[2] GENG Wei, LU Yong. The cause analysis and treatment of a inner discharge case caused by moistened 35kV switchgear. Electric Switchgear, No.4, 65-66,2008(4).

[3] YAN Qun. Design and analysis of insulation structure of solid insulation switchgear. Mechanical Research \& Application, No.5,77-80,2009.

[4] Xiao-yu Wang, Xin Lin, Jian-yuan Xu, Yong-xiang Li. Research on the Control Technique of the Permanent Magnet Linear Servo Motor Operating Mechanism of High-voltage Circuit Breaker. ICAL,Shenyang.465-470,2009.

[5] WEN Kang-zhen, WEN Yuan-fang, DUANMU Lin-nan, et al. The error of ANSYS solution of electrostatic field produced by sharp electrode. Insulators and Surge Arresters, No.2,14-16,2009.

[6] D. Z. Cheng, Controllability of switched bilinear systems, IEEE Trans. on Automatic Control, Vol.50, No.4, 511-515, 2005. 